\title{
Indicators and Managing for Results: Filling the Gap in Coach Transport Services
}

\author{
MAGALHÃES, Marcos Thadeu Q. ${ }^{1}$ \\ GULARTE, Juliana ${ }^{2}$ \\ YAMASHITA, Yaeko ${ }^{3}$ \\ ARAGÃO, Joaquim José Guilherme de ${ }^{4}$ \\ 1Faculty of Architecture and Urbanism, University of Brasilia, Brasilia, Brazil. marcosthadeu@unb.br \\ 2University of Brasilia, Brasilia, Brazil. jggularte@hotmail.com \\ 3University of Brasilia, Brasilia, Brazil. yaeko@unb.br \\ ${ }^{4}$ University of Brasilia, Brasilia, Brazil. aragao@unb.br
}

\section{Resumo}

Este artigo discute a Gestão por Resultados (MFR, no inglês) em contratos de serviços de transporte de passageiros. Apresenta o Processo Integrado de Planejamento e como é possível unir, num único quadro, planejamento, monitoramento e avaliação. Após isso, são propostos um conjunto de indicadores de desempenho capazes de cobrir tanto os requisitos de gestão processual quanto finalística. Ao fim, comenta-se sobre os principais limitadores da proposta bem como fatores críticos de sucesso para a Gestão por Resultados voltada para os contratos de serviço de transporte de passageiros.

Palavras-Chave: Gestão por Resultados; Transporte de Passageiros; Indicadores; Avaliação; Planejamento Orientado a Resultados.

\begin{abstract}
This paper discusses MFR (Managing for Results) in Coach Transport Contract Management. It presents an Integrated Planning Process and shows how it is possible to merge planning, monitoring and assessing activities into one single framework. After that, we propose a set of performance indicators that are able to cope with both procedural and finalistic performance management requirements. Finally, we comment some limitations of the research and present some critical factors for success of MFR in Coach Transport Contract Management.
\end{abstract}

Key-Words: Managing for Results; Coach Transport Services; Indicators; Evaluation; ResultOriented Planning. 


\section{Introduction}

Performance assessment in interurban coach transport contract is still non-consensual ground. The polemic starts from the proper definition of performance and may also embrace the regulatory policy. As to the definition aspect, the question is whether the definition of the term 'performance' must include finalistic aspects or not. With respect to the regulatory implications, the issue is concentrated on listing the aspects that should, or should not, be controlled by the regulatory agent.

These issues imply two different approaches in discussing performance: the first one deals with monitoring performance and the setting up of proper indicators for that purpose; the other one, with straightforward control of deterministic performance factors in order to assure the quality and reliability of the service provided. Depending on the approach, two different classes of indicators for assessing performance in interurban transportation contracts may be set up: finalistic indicators and procedural indicators.

When designing interurban coach transport contracts, two things are to be made clear: what are the correct outputs expected (which means defining 'what is a good service'), and to what extent the process of operation has to be monitored or controlled. The first issue leads to the definition of the proper function of the service, its actual aims, and to the measuring of its effectiveness. The latter provides the operation-related risks that the regulator is willing to accept.

In general, indicators are expected not only to function as a tool for control systems, but also to plan them. In their control function, the indicators serve as signal for the need for intervention in the system. In their planning function, the indicators lead to the production of relevant information in order to assess if the system will provide the correct outputs. In any case, they must be understood as synthetic elements and do not cover every aspect of the operation, otherwise, an excess of detail will make and the whole assessment mechanism unfeasible and ineffective.

The proposed paper addresses the problem of assessing performance in interurban coach transport contracts, by covering both effectiveness and operation-related issues. Thus, it is structured as follows: (i) performance indicators and performance management; (ii) monitoring and control as part of a comprehensive planning framework; (iii) particularities of interurban coach transport; (iv) result-oriented and process-oriented approach in contract management; $(v)$ proposed scope and use of performance indicators for interurban transport contracts; (vi) conclusions and further research.

\section{Performance, Indicators and Performance Management}

The term 'performance' is associated to the idea of how successful an action, process or operation is. In this broad sense, no further definition is required.

However, when entering the field of performance management, that general idea of performance is no longer enough to support practical requirements. To clarify this, we should look at the issue of managing performance in more detail.

Performance Management discipline (if we can call it so) became very important with the advent of the public sector reform called MFR (Managing for Results). Such reforms spread worldwide and many countries like OECD countries, US, and developing countries such as Brazil adopted it. But along with the MFR paradigm many issues on implementing it arouse. Moynihan and Ingraham (2003) analysed experiences with MFR in the public sector and pointed out that:

- The adopted measures allowed increasingly precise explanation of what was measured, but did not reveal why measures reflected good or bad performance;

- The focus of measurement did not permit analysis of potential capacity to perform or the extend to which objectives measured reflected priorities and objectives that were present throughout the design and implementation processes;

- For an MFR system be effective, there must be a commitment to purposes, processes and outcomes; 
- Consensus building is a key factor in the success of a MFR strategy.

Boyne \& Chen (2006) discussed other issues related to MFR implementation, especially the role of setting targets on the performance outcomes. They observed that the setting of targets has positive impacts on performance, and also, that setting challenging targets brings in better results than setting easy ones. However, with the collected data, they could not conclude if many targets are better than few, despite the fact that their study pointed to better results related to a greater number of targets.

Boyne \& Chen (2006) observed that many experiences and studies in MFR are still restricted to approaching processes rather than outcomes. Such limitations can have an obscuring effect on correctly evaluating performance as it would be possible to have a process that was efficient in generating the specified products but, on the other hand, those products might be unable to generate the desired outcomes. Such connection and arguing on the purpose or the outcome is a teleological approach. Magalhães et al (2007) gives a general framework for establishing such connections for transport services.

\subsection{Indicator Defined}

The term "indicator" is widely used both in the academic and professional environments, and by public authorities and private companies alike. This popularity results from a planning process that comprises different decision levels (strategic, tactical and operational) and information management becoming more accessible. Information management allows knowledge to be delivered to whom, and when it is needed.

Indicators are concise, easy-to-read representative parameters used to illustrate the main characteristics of a given object of study (CEROI c.f. Magalhães et al, 2005). In addition, indicators are variables that have a social significance in addition to their scientific connotation, thus reflecting a social concern in the decision making process (MMA-Espanha c.f. Royuela, 2001). According to Royuela (2001), the purposes of an indicator are: (i) to provide information on problems on hand; (ii) to subsidize policy development and setting priorities, spotting key factors; (iii) to contribute to follow-up on the measures that have been taken and, (iv) to be a tool for disseminating information at all levels.

\subsection{Types of Indicators}

In order to cater for different information needs and support different sorts of analyses there are many types of indicators. They can be classified according to the level of analysis they deliver and to their purpose or representative dimension. When classified according to their representative dimension, indicators can be defined as descriptive, performance, efficacy or efficiency indicators (EEA, 1999). The types of indicator are summed up in Table 1.

Table 1: Types of Indicators.

\begin{tabular}{|c|c|}
\hline Type of Indicator & Overview \\
\hline $\begin{array}{l}\text { Descriptive } \\
\text { Indicators }\end{array}$ & $\begin{array}{l}\text { These indicators describe or } \\
\text { characterize a given topic. They } \\
\text { reflect the situation as it is, } \\
\text { without reference to how the } \\
\text { situation should be. }\end{array}$ \\
\hline Efficacy Indicators & $\begin{array}{l}\text { These indicators compare actual } \\
\text { conditions with a specific set of } \\
\text { reference conditions. They } \\
\text { measure the 'distance' between } \\
\text { the current situation and the } \\
\text { desired or target situation. }\end{array}$ \\
\hline Efficiency & $\begin{array}{l}\text { These indicators provide insight in } \\
\text { the efficiency of products and } \\
\text { processes. Efficiency in terms of } \\
\text { the resources used and waste } \\
\text { generated per unit of desired } \\
\text { output. }\end{array}$ \\
\hline
\end{tabular}

Source: Adapted from EEA (1999).

\subsection{The role of indicators in the MFR approach}

'Strategic planning without performance measurement fails to link goals to actions or identify implementation issues, failures that generate a lack of credibility among stakeholders' (Moynihan \& Ingraham 2003). Thus, performance indicator design is determinant in the success of an MFR system as they are the linking points between planning, implementation, monitoring, communication and evaluation.

When building MFR systems, integrating actions must ensure that strategic goals link to performance measures, that performance 
information is formulated in a way to be useful for decision venues, and that performance information actually reaches desired venues (Moynihan \& Ingraham 2003).

Magalhães et al (2007) proposed a preliminary sketch of a panel of transport performance indicators whose scope would be stable through time, consequently rendering the data-gathering process cheaper. Those indicators are outcomebased, and process performance indicators could be derived from them. The benefits of such a set is that it links both process and outcome performance evaluation that, according to Boyne \& Chen (2006), is an issue that has been neglected in MFR implementation.

\section{Planning for MFR on Coach Transport Contracts}

\subsection{The Proposed Approach to Planning}

The Figure 1 below presents a diagrammatic model of planning that attempts to incorporate both auditing and planning approaches into a single concept chart.

Figure 1: Integrated Planning Process.

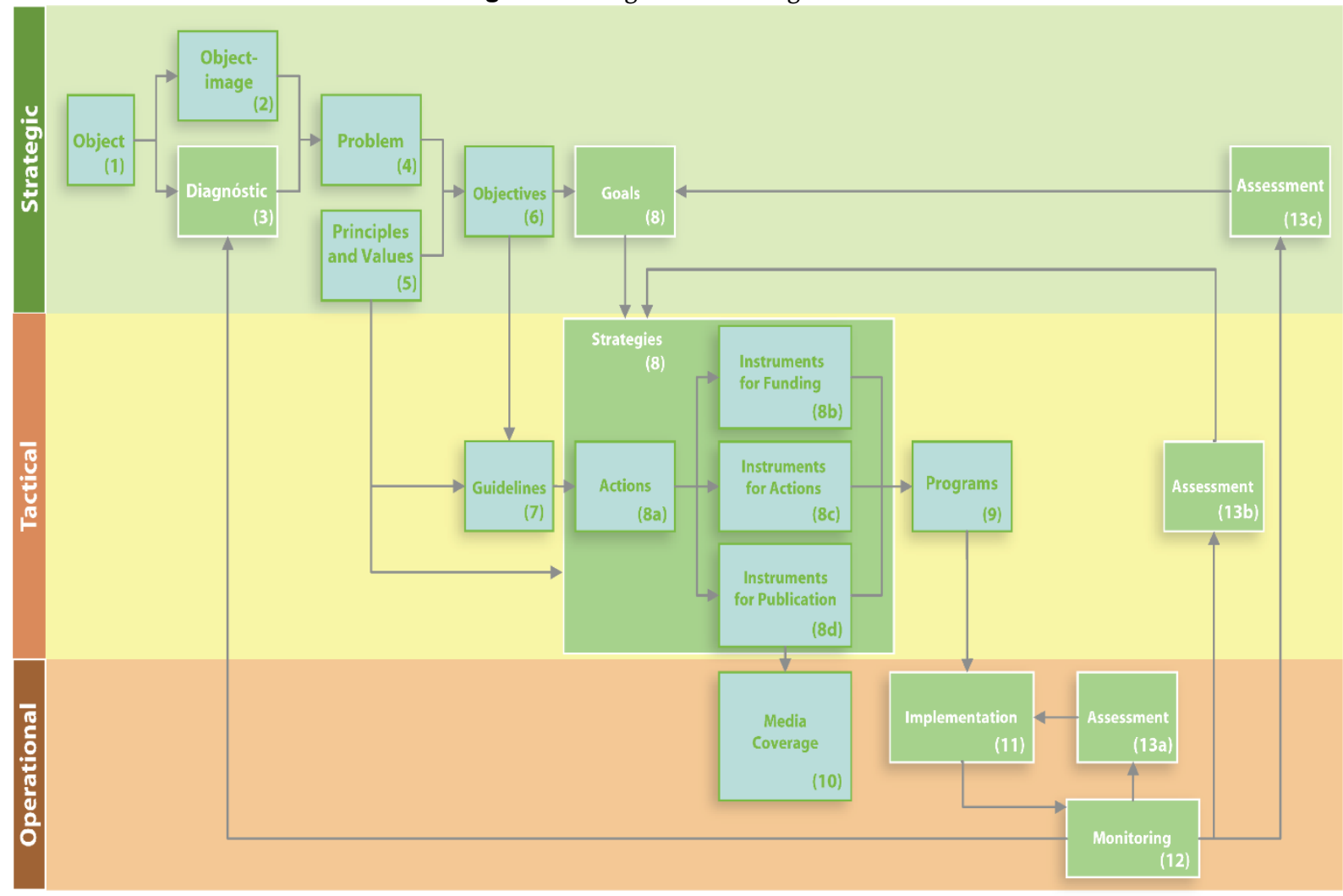

Source: Magalhães (2009).

The following observations refer to the figure:

- Decision makers play a vital role in the planning process, especially at strategic and tactical levels, to ensure that the plan's scope is a true social-political commitment;

- There cannot be any planning without clearly defining and delimiting the Object to be Planned;

- At a strategic level, "what to do" is defined; at a tactical level, "how to do it"; at the operational level the plan is implemented;

- Programs result from strategy specification. They have a single objective (result or outcome) - i.e., a specific change in the present state of affairs. They have their mechanisms of funding and means of action clearly defined together with their instruments of publication;

- Monitoring provides data input for the 
different assessment levels. Data are gathered during this stage;

- There are 4 cycles of assessment and revision: (1) operational, assesses execution and implementation procedures; (2) tactical, determines how appropriate the strategies and programs have been; (3) strategic, follows up on goal achievement, and determines how feasible the initially established goals were; (4) structural, verifies the diagnosis and, consequently, identifies problems and redefines the Plan's objectives.

\subsection{Some Core Premises}

We will assume the following premises on the development of our method for managing public services contracts:

- P1. Each contract has a motivation, to which it is linked. This motivation provides the basis for listing the expected outcomes that have to be accomplished.

- P2. There are restrictions towards the accepted means for generating the expected outcomes.

Both $\mathrm{P} 1$ and $\mathrm{P} 2$ are required to manage a public service contract. If $\mathrm{P} 1$ is to be ignored, there can be no MFR. If on the other hand, P2 is to be ignored, no procedural auditing is possible or required.

P1 stands for the fact that each public service contract should be motivated by some necessity and be designed to satisfy such needs. In case of coach transport contracts, as presented in Magalhães et al (2007), they should provide mobility, and an effective transport service.

On the other hand, P2 stand for the fact that it is not acceptable that the service be provided without concern for its processes. This is corroborated by ISO certification requirements in certain contexts.

Assuming these premises, we can understand why contracts should be linked to planning, monitoring and controlling activities. In the following section, we explore the idea of integration among planning, monitoring and controlling.

\section{Monitoring and Controlling as Part of a Comprehensive Planning Framework}

While analyzing the official planning method adopted by the Brazilian Government, Magalhães \& Yamashita (2009) stress that the disconnection among planning, monitoring and assessing is the limiting issue to performance management, especially the MFR focus. Also, Moynihan and Ingraham (2003) point to the fact that most of MRF experiences worldwide have failed to cope with the outcome (or result) assessment, being limited to process evaluation. We advocate that, in order to cope with MFR expectations, evaluation and control processes should be integrated within the planning model.

To accomplish that we adopt the Comprehensive Planning Framework for MFR in which the assessment and monitoring activities are made part of such framework, and they are also interconnected with the development of the whole plan and its implementation and revision.

Although Magalhães \& Yamashita (2009) did not propose it explicitly, we propose that under this framework two different assessing processes should be conducted: (1) process assessment, which is focused on the products and product-related performance measures; (2) result (or outcome) assessment, which is focused on the outcomes of the whole process and on result-related measures.

At this point, it must be made clear that both monitoring and assessment processes are of infrastructural importance to the controlling system as a whole. And also, there can be no MFR without inputs and evaluation.

Thus, under this Integrated Planning Framework, activities such planning, managing and controlling are fully integrated. For example, the inputs provided by the management activities feed the process-oriented control activities. Also, under this framework, both process and outcome controls are performed.

As final comments on this topic, we should stress that management and control are activities that transect all decision levels and their respective jurisdiction. Programs are reference units for 
managing the plan, and activities standards and indicators for the state of affairs are reference units for controlling the plan.

\section{Result-Oriented and Process Oriented Approaches}

Control is the activity that allows the planner: to assess the results of the plan's implementation, to identify problems, and to change what is required. As the contracts are motivated by issues identified during the plan's elaboration, control is necessary to assure a successful plan and also to assure that each contract plays its role accordingly. To that end, there are two different kinds of control: (1) procedural, that focus on the products generated by the processes; (2) finalistic, which focus on the outcomes generated by the products. It is clear that these two kinds of controls are interrelated, even thought much more knowledge and documentation exist on the first one (Moynihan and Ingraham, 2003; Boyne \& Chen, 2006).

\subsection{Procedural Control}

Procedural control is the activity that monitors the executed processes to provide an expected product. It assesses if the predicted products were generated (efficacy) and if the processes have generated most products with least resources (efficiency). Thus, the focus here is directed at resources, processes, products and the relations among them, ignoring the outcomes however.

In the Comprehensive Planning Framework, procedural control is located at the operational level, corresponding to the standard's definition, definition of execution procedures, and also for the effective implementation of such rules. Thus, the role of this kind of control is to assure that processes be carried out as expected and generate the defined products. Procedural control is consists of two main activities: (i) Auditing (which comprehends both monitoring and verifying); and (ii) Assessment.

Figure 2: Procedural control in the Integrated Planning Process

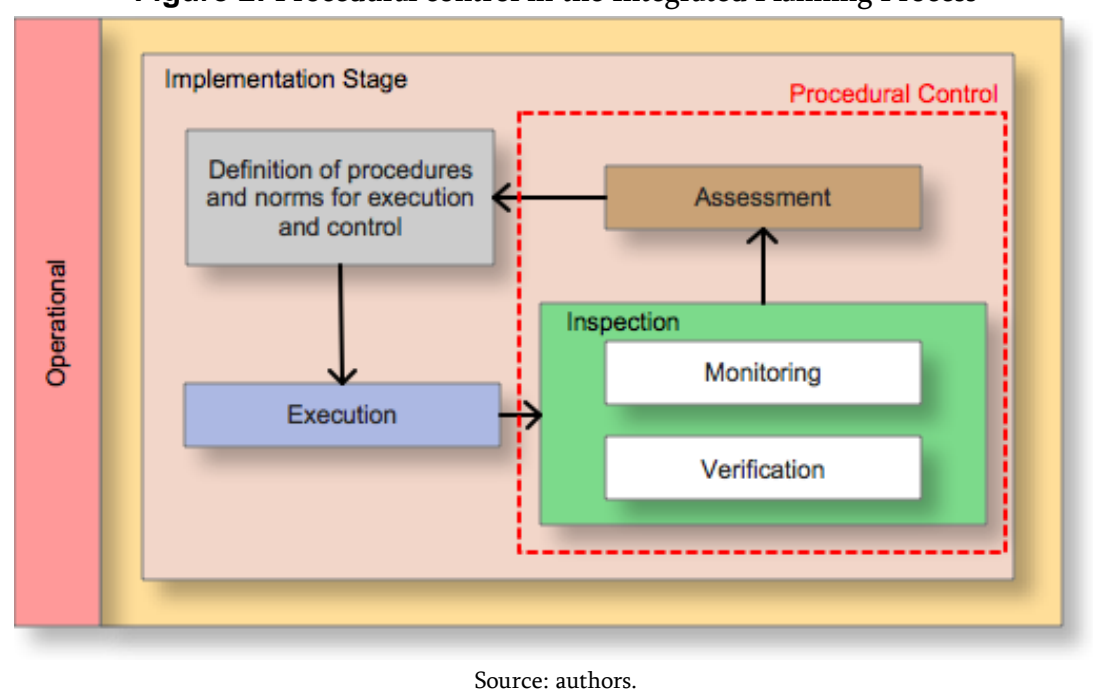

\subsection{Finalistic Control}

Finalistic control is the activity that monitors the object of planning, in this case, the interurban coach transport service. According to MFR, it verifies the achievement of the expected outcomes (defined during the strategic level of the planning process). Thus, finalistic control audits to what extent the implemented actions have produced the desired effects, allowing plans' evaluation and revision (TCU, 2000).

In the Integrated Planning Framework, finalistic control comprehends a monitoring process which feeds four different Evaluation and Revision Cycles, each one drawing attention to each level of planning (strategic, tactical and operational).

The four Evaluation and Revision Cycles are:

- Operational Cycle: in which data from monitoring feed the implementation evaluation procedures (Magalhães \& Yamashita, 2009). Therefore, operational level evaluation assesses how norm and 
execution procedures, programs, projects and actions (including those from the procedural control) have contributed to the achievement of the desired outcomes (as we will discuss, such outcomes are mobility, and efficacy and efficiency of transport).

- Tactical Cycle: in this cycle, data generated from monitoring are used to assess whether the adopted strategies were adequate, and how they have contributed to the achievement of the expected results (Magalhães \& Yamashita, 2009).

- Strategic Cycle: this cycle uses data generated by monitoring to follow the achievement of the goals defined in the plan. It assesses if the goals were feasible and possible to be achieved and harmonizes such goals with more precise and realistic measures.

- Structural Cycle: this cycle uses data from monitoring to update diagnostic and problem identification. It also sets new objectives to be pursued (Magalhães \& Yamashita, 2009). In short, it revises the plan from the perspective of its fundamental issues.

\subsection{Control and Contract Management}

As previously commented, the MFR paradigm comprises process and result control, and both of them have to be considered in managing performance in interurban coach transport contracts. The main reason is that by doing so it would not allow a contract to be considered efficient and effective without assessing it's ultimate results, such as providing mobility and a safe and sustainable transport.

Again, as Boyne \& Chen (2006) stress, the international experience on MFR is still limited to procedural control, lacking the other side of it: the finalistic control. Our proposed set of indicators for interurban coach transport contract performance management is intended to cover both dimensions of control, thus leading to an effective MFR experience. This proposal is presented in the next section.

\section{Proposed Scope and use of Performance Indicators for Interurban Transport Contracts}

\subsection{General concepts for the set of indicators for finalistic control: the teleological structure of transportation planning}

This section presents the teleological structure underlying the set of finalistic control indicators. The main postulation we assume is that planning is a rational action in itself, and therefore it supports this teleological approach.

Considering the new approach to planning, Magalhães et al (2007) present a proposal for teleological structure that comprises three fundamental elements, which should be the main purposes of transportation planning, and in our case, the main results expected from a interurban coach transport service contract implementation.

In general terms, they are: Mobility, Transportation Efficacy and Transportation Efficiency. Mobility is the ability to be transported (Magalhães \& Yamashita, 2006). Transportation Efficacy means that, when transport does take place, it is successful. Theoretically, in a situation where there is full mobility, all objects (people and freight) may be transported when necessary. However, this does not mean that transport is successful. The idea of "success" is the same as that of "efficacy" (Magalhães et al, 2007). And Transportation Efficiency means that the transport process is carried out in the most economical way possible. (Magalhães et al, 2007). 
Figure 3: Transportation Planning Objectives.

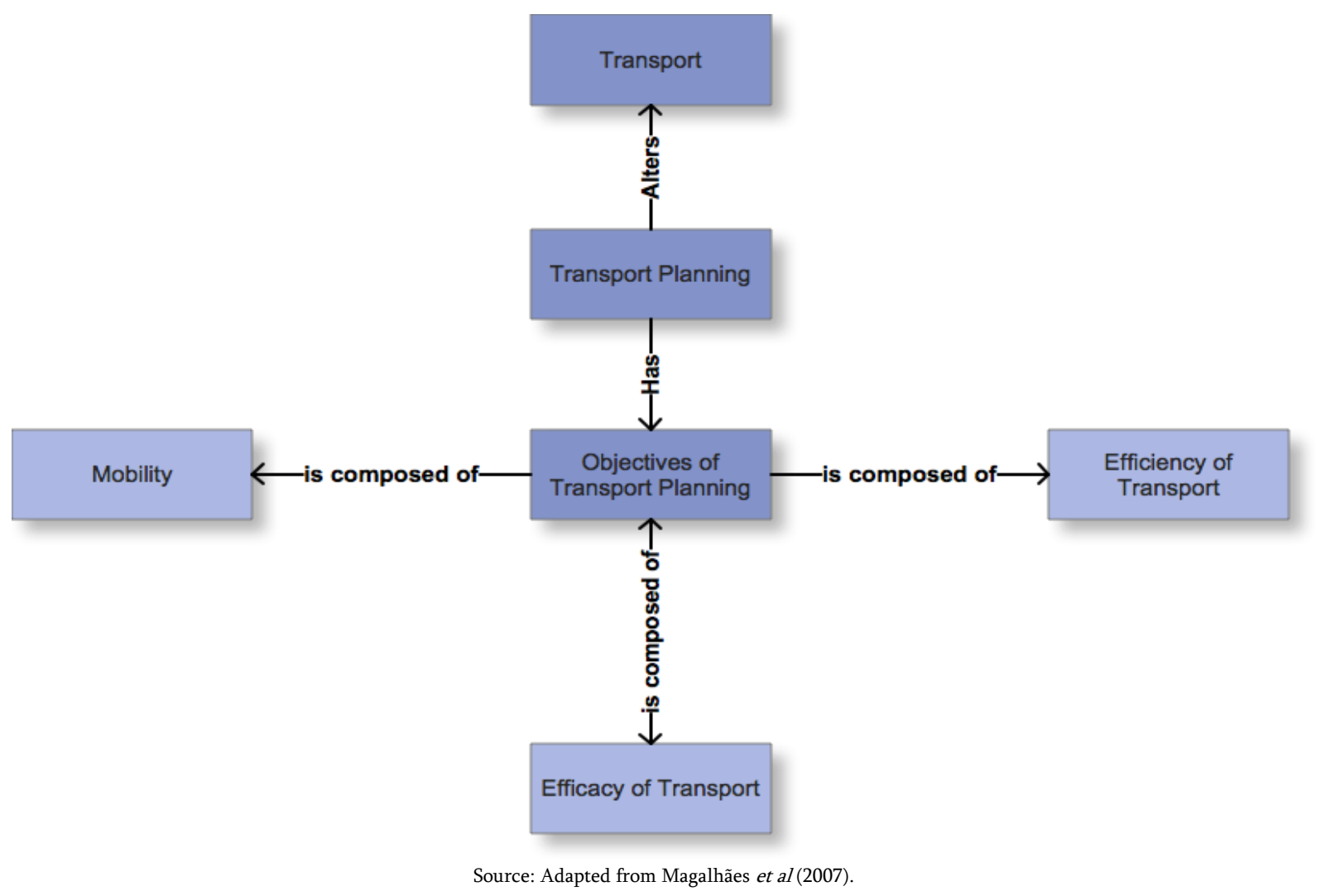

\subsection{Finalistic and Indicators for Managing Performance of Interurban Coach Transport Contracts}

contract performance management must cover both finalistic and procedural issues. Figure 4 bellow illustrates this idea.

As has been previously argued, coach transport

Figure 4: Main issues to be covered by indicators for coach transport contract performance management.

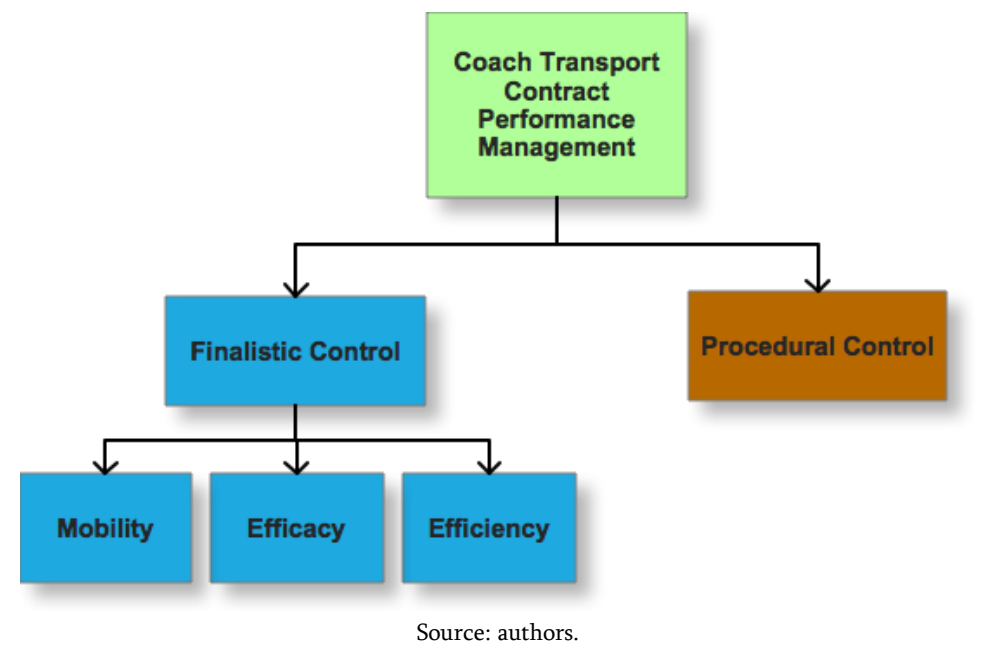

In this section, we present the proposed indicators, categorized into finalistic and procedural indicators. Some of these indicators have already been introduced in Magalhães et al (2005).

\subsubsection{Procedural Indicators}

The proposed procedural indicators are meant to cover formal aspect of the service provision (most of them related to quality issues) and the status of the contractor in relation to legal issues. The scope 
of indicators is very simple, and we try to avoid issues that have high grade of subjectivity (i.e. user satisfaction, in fact we advocate that this data should be considered elsewhere in the planning process, but not in contract performance management, because the mechanism of satisfaction is not fully known, and it is affected by other things apart from the quality of the service provided by the contractor).

Table 2: Procedural Indicators

\begin{tabular}{|c|c|c|c|}
\hline Focus & Issue & Indicator & Description \\
\hline \multirow[t]{4}{*}{$\begin{array}{l}\text { Procedural } \\
\text { Control }\end{array}$} & $\begin{array}{l}\text { Up-to-date } \\
\text { equipment }\end{array}$ & $\begin{array}{l}\text { Certificates of compliance } \\
\text { with ISO or other } \\
\text { standards for equipment }\end{array}$ & $\begin{array}{l}\text { Indicates if the } \\
\text { contractor updates its } \\
\text { equipment to comply } \\
\text { with the latest standards. }\end{array}$ \\
\hline & $\begin{array}{l}\text { Up-to-date } \\
\text { techniques }\end{array}$ & $\begin{array}{l}\text { Certificates of compliance } \\
\text { with ISO or other } \\
\text { standards for processes } \\
\text { and techniques }\end{array}$ & $\begin{array}{l}\text { Indicates if the } \\
\text { contractor updates its } \\
\text { processes and techniques } \\
\text { to comply with the latest } \\
\text { standards. }\end{array}$ \\
\hline & Legality & $\begin{array}{l}\text { Number of prosecutions } \\
\text { or fines charged on the } \\
\text { contractor }\end{array}$ & $\begin{array}{l}\text { Represents the number } \\
\text { of legal unconformities } \\
\text { related to the contractor. }\end{array}$ \\
\hline & $\begin{array}{l}\text { Up-do- } \\
\text { date } \\
\text { vehicles }\end{array}$ & $\begin{array}{l}\text { Certificates of compliance } \\
\text { with ISO or other } \\
\text { standards for vehicles }\end{array}$ & $\begin{array}{l}\text { Indicates if the } \\
\text { contractor updates its } \\
\text { processes and techniques } \\
\text { to comply with the latest } \\
\text { standards. }\end{array}$ \\
\hline
\end{tabular}

Source: authors.

In short, these indicators are meant to answer the following question: "Does the contractor inspires confidence in providing a good service?" A contractor that doesn't have up-to-date vehicles, processes and techniques and equipment does not inspire confidence. Furthermore, a contractor that is constantly being prosecuted for not complying with the legal requirements does not inspire confidence either. Also, it is not sufficient to comply with those aspects once in a lifetime: they are properties that have to be sustained while the contract endures, and indeed, to guarantee that the contract will endure.
It is important to stress that in some countries, failure to complying with these requirements is sufficient reason for terminating a contract, and therefore, they must be taken into account in performance management.

\subsubsection{Finalistic Indicators}

As we have seen, procedural indicators are only one side of the coin. The finalistic indicators are the other side, and maybe the most important ones. These indicators are presented grouped by main categories: Mobility, Efficacy and Efficiency.

Table 3: Finalistic Indicators

\begin{tabular}{|c|c|c|c|c|}
\hline Focus & \multicolumn{2}{|c|}{ Issue } & Indicator & Description \\
\hline \multirow[t]{4}{*}{$\begin{array}{l}\text { Finalistic } \\
\text { Control }\end{array}$} & \multirow[t]{2}{*}{ Mobility } & Affordability & $\begin{array}{l}\text { Ratio between service fare } \\
\text { and user income }\end{array}$ & $\begin{array}{l}\text { Represents the ratio between the price charged } \\
\text { by the operator and the income of the user, } \\
\text { indicating how affordable the service is. }\end{array}$ \\
\hline & & Comfort & $\begin{array}{l}\text { Vehicle compliance with } \\
\text { comfort standards } \\
\text { Vehicle compliance with } \\
\text { hygiene standards } \\
\text { Vehicle compliance with } \\
\text { safety standards }\end{array}$ & $\begin{array}{l}\text { Represents the proportion of the fleet that meets } \\
\text { defined comfort standards. } \\
\text { Represents the proportion of the fleet that meets } \\
\text { defined hygiene standards. } \\
\text { Represents the proportion of the fleet that meets } \\
\text { defined safety standards. }\end{array}$ \\
\hline & \multirow[t]{2}{*}{ Efficacy } & Reliability & $\begin{array}{l}\text { Reliability of on reaching } \\
\text { the destination }\end{array}$ & $\begin{array}{l}\text { Ratio between completed trips (those that } \\
\text { reached the destination) and started trips. }\end{array}$ \\
\hline & & Safety & $\begin{array}{l}\text { Number of victims in } \\
\text { accidents }\end{array}$ & $\begin{array}{l}\text { The sum of all victims related to the services } \\
\text { provided by the operator. }\end{array}$ \\
\hline
\end{tabular}




\begin{tabular}{|c|c|c|c|}
\hline & & $\begin{array}{l}\text { Number of accidents per } \\
\text { traveled distance }\end{array}$ & $\begin{array}{l}\text { The ratio between the number of accidents and } \\
\text { the traveled distance related to the service } \\
\text { provided by the operator. }\end{array}$ \\
\hline & & Lost or damaged luggage & $\begin{array}{l}\text { The occurrences of loss or damage to passenger's } \\
\text { luggage during the service provision. }\end{array}$ \\
\hline & Punctuality & Punctuality on departure & $\begin{array}{l}\text { Indicates the time gap between scheduled time } \\
\text { and effective departure time. }\end{array}$ \\
\hline & & Punctuality on arrival & $\begin{array}{l}\text { Indicates the time gap between scheduled time } \\
\text { and effective arrival time. }\end{array}$ \\
\hline \multirow[t]{6}{*}{ Efficiency } & $\begin{array}{l}\text { Energy } \\
\text { expenditure }\end{array}$ & Energy productivity & $\begin{array}{l}\text { The mean value for the ratio between } \\
\text { combustible amount and total traveled distance } \\
\text { for the services. }\end{array}$ \\
\hline & Emissions & Greenhouse Gas emission & $\begin{array}{l}\text { The estimated amount of greenhouse gases } \\
\text { produced during service provision. }\end{array}$ \\
\hline & & $\begin{array}{l}\text { Particles and dust } \\
\text { emissions }\end{array}$ & $\begin{array}{l}\text { The estimated amount of particles and dust } \\
\text { material produced during service provision. }\end{array}$ \\
\hline & & Noise emission & $\begin{array}{l}\text { The estimated upper level of noise emitted } \\
\text { during service provision. }\end{array}$ \\
\hline & Frequency & Frequency of the service & The amount of trips offered in a time interval. \\
\hline & Travel Time & Travel time (mean) & $\begin{array}{l}\text { The mean value of time required to cover the } \\
\text { distance between a OD pair. }\end{array}$ \\
\hline
\end{tabular}

Finalistic indicators aim to answer the question: "How good is the service offered by the contractor?". Although many other indicators could be considered (i.e. user satisfaction), we tried to restrict the scope on indicators to those with higher degree of objectivity and with a feasible measurement process. In fact, in a regulated context, failure to satisfy users would just show up in the first set of indicators under "Legality" issue.

These indicators are meant to cover the assessment of outcomes of a contract, a matter that has been not properly addressed in current practices. With both sets of indicators, it is possible to determine whether a contract should be continued or terminated, or whether some corrective actions should be necessary. As commented in the beginning of this paper, the correct use of indicators is essential to a effective planning process. Thus, we close the cycle of planning, linking it to monitoring and assessment processes.

\section{Conclusions and Further Research}

The indicators presented in this paper have not yet been fully applied to contract design. However, they are based on important lessons learned from current practice, and those from theoretical advances in the field of planning and managing for results. It must be remembered that assessment of outcomes is still far from being a common activity in the public sector, as was commented at the beginning of this paper. We are trying to move ahead on this matter.

In the design of the contract, reference measures have to be set in order to allow for MFR. Otherwise, there could be monitoring of the indicators with no targets and no performance reference values, thus rendering results management an impossible task. Targets have to be feasible, but also challenging. Boyne \& Chen (2006) have discussed the effects of setting targets on the performance of a public service.

At this point, we should stress other critical factors for the success of MFR:

- Benefits and penalties have to be linked to performance indicator measures (otherwise, no one would worry about them);

- Monitoring systems must work and be reliable (or assessing indicators would be impossible or unreliable);

- Both procedural and finalistic performance must be considered;

- Lessons in contract management must be considered at strategic and tactical levels;

- In the case of good or bad performance, the manager must act as stated in the 
contract - by giving the promised benefits or applying the corresponding penalties (otherwise, there would be no incentive to comply with the contract terms).

Finally, more experiences on successful MFR in Transport should be documented properly in order to increase our knowledge base for future contract design.

\section{References}

Boyne, G. A. \& Chen, A. A. (2006). Performance Targets and Public Service Improvement. Journal of Public Administration Research and Theory, 17, 455-477.

EEA - European Environment. Environmental (1999) Indicators: Typology and Overview. EEA, Copenhagen.

Magalhães, M. T. Q.; Yamashita, Y.; Teixeira, G. L.; Carneiro, L. G. P. L. (2005). Development of an Indicators System for Quality Management of the Interstate and International Coach Transportation Service in Brazil. In Macario, R. (ed.) Competition and Ownership in Land Passenger Transport: Selected Papers from the 9th International Conference. Elsevier, Oxford.

Magalhães, M. T. Q., Silveira, L. S., Galindo, E. P., Gomes, H. A. S., Villela, T. M., Yamashita, Y., Aragão, J. J. G. (2007). Teleological Framework for Transport Planning and Evaluation: A Tool in the Search for Integrated and Meaningful Solutions for Better Results. Thredbo 10.

Magalhães, M.T.Q. \& Yamashita, Y. (2009). Repensando o Planejamento (Rethinking the Planning Process). Textos para Discussão - Ceftru, 4, 1-30.

Moynihan, D. P. \& Ingraham, P. W. (2003). Look for the Silver Lining: When Performance-Based Accountability Systems Work. Journal of Public Administration Research and Theory, 4, 469-490.

Royuela, M. A. (2001). Los Sistemas de Indicadores Ambientales y su Papel em la Información e Integración Del Medio Ambiente. I Congreso de Ingeniería Civil, Territorio y Medio Ambiente, 1231-1256.

Tribunal de Contas da União - TCU (2000). Manual de Auditoria de Natureza Operacional do Tribunal de Contas da União. Tribunal de Contas da União. COFIS/SEGECEX, Brasília. 